\title{
Deixis in Polite Interaction
}

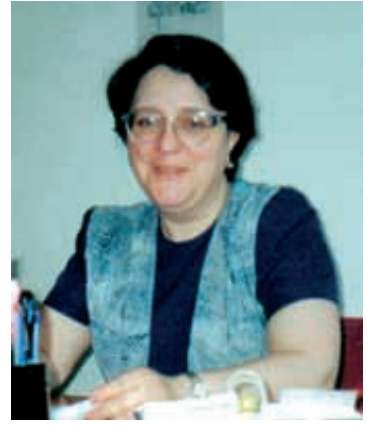

Yelena Yerznkyan

T inguistic interaction is necessarily social interaction. LIt has been repeatedly proved empirically that language as the major means of human communication fulfills many different goals. We communicate factual information, ideas, as well as beliefs, emotions and attitudes or any other socially meaningful content in our everyday interaction. We construct, establish and maintain social relationship within various social contexts by performing speech activities and employing appropriate language means to ensure harmonious interpersonal relations and cooperation.

One important socio-cultural aspect which speakers may convey is that of politeness, which can be expressed using various linguistic as well as nonlinguistic strategies.

Every culture has developed various linguistic means to mark the politeness intentions of the speaker. Moreover, every culture has its own understanding of what constitutes "polite" and socially "appropriate" linguistic behaviour. The latter is determined by culture-specific values and is supposed to be shared by all members of the community.

It is universally recognized that the language of politeness cannot be dissociated from the social relationship between the speaker and the hearer. And from this point of view deixis understood as a linkage between the utterance and its spacio-temporal and personal context plays a crucial role in politeness as a language category.

In this paper the concept of politeness will be dealt with with reference to the deictic means of expressing various degrees of politeness. Although there is a comprehensive literature on politeness, little work has been done to reveal the interrelation between these two linguistic categories.

For an adequate observation of the relationship between deixis and politeness, one should first clarify the fundamental notion of politeness and that of deixis.

Linguistic politeness as a field of study has always attracted attention among researchers of different schools, perhaps because of its almost universal relevance to the activities of everyday life.

The politeness principle plays an essential role in a social interaction where basically the speaker and the hearer (addressee) are involved. In the utterance conveying politeness, the speaker's attitude towards the social context of the interaction is reflected. It covers "the speaker's relationship with and sensitivity toward the hearer, the importance of the information to be conveyed, the formality of the situation, and the effect the speaker wishes to achieve via utterance” (Koike, 1989: 189). 
At present most accounts of politeness are probably based on speaker-addressee relationship. Communication is regarded as a cooperative speech act. The aim of communication is to achieve mutual understanding. This cannot be reached unless participants/interlocutors take into account each other's interests. And language use being a form of joint action raises issues of equity and face. Speakers and listeners must carry out actions as individuals if they are to succeed in their use of language. But they must also work together as participants in the social units (Clark, 1996 316-317).

The notion of politeness being crucially based on the degree of speaker's sensitivity to the hearer/addressee much depends on the choice of deictic means to express one's intentions.

The distinction between 'speaker-centred' and 'addressee-centred' utterances comes to discriminate different degrees of politeness. It can be said that to be sensitive to the addressee for the speaker means to take the addressee as a "central person' or "person of importance' in interactions.

Different politeness theories sharing commonly the 'addressee-centred' notion have been proposed by R.Lakoff (1973, 1974), Brown\&Levinson $(1978,1987)$ Leech (1983), who treat politeness as "strategies for conflict avoidance". These theories support the notion of 'face' which was proposed by Goffnan (1967).

In order to enter into social relationship, we have to acknowledge and show an awareness of the face, the public self-image, the sense of self of the people that we address. This is considered a universal characteristic across cultures: speakers should respect each other's expectations regarding self-image, take account of their feelings, and avoid face-threatening acts.

This means that politeness has to do with how the interlocutors deal publicly with each other's self-worth and autonomy. People manage face by trying to maintain both their self-worth, to be respected by others, and their autonomy, to be unimpeded by others. How polite the interlocutors are depends on the cooperation of the other. The politeness of each depends on the actions of both. Equity and face appear to constrain all actions that require joint commitments.

In our discussion we have incorporated the ideas of Brown \& Levinson, and Leech on politeness in that this social phenomenon is being examined for its pragmatic and language manifestations within the social context of the dynamic relationship between the speaker and the hearer. For our purposes politeness may be defined as the function of language to imply the most appropriate speaker-addressee relationship through the use of communicative stralegies recognized by the sociely as carrying a particular illocutionary force.

The notion of deixis is based on the fact that "every language utterance is made in a particular place and at a particular time: it occurs in a certain spacio-temporal situation" (Lyons, 1968: 275). Deixis has basically three categories: person, place, and time. To these categories two more are added: 'discourse deixis' and 'social deixis'. The 'discourse deixis' is concerned with "the encoding of reference to portions of the unfolding discourse in which the utlerance (which includes the text referring expressions) is located." The 'social deixis' has to do with "the encoding of social 
distinctions that are relative to participant-roles, particularly aspects of the social relationship holding between speaker and addressee(s) or speaker and some referent" (Levinson $1985: 62-63$ ). The deictic expressions proper generally have the centre on the speaker. Speaker orientation is usually expressed by the personal pronoun $I . I$ is considered the deictic centre pointing to the one who is speaking. J. Lyons points to the egocentricity of speech acts by stating that it is "egocentric in the sense that the speaker casts himself in the roles of ego and relates everything to his viewpoint" (Lyons. 1977: 638). $I$ is needed for specifying the agent of all locutionary, illocutionary, and perlocutionary acts.

Let us look more closely at this 'egocentric' focus, which is part of the semantic concept of deixis. The mentioned three types of deixis - person, place and time - are all oriented to the speaker's point of reference, which constitutes the deictic centre. At the same time, it should be noted that the centre of orientation of the utterance, based on the speaker's point of view, may be shifted in different ways to convey certain meanings.

Thus, from a broader sense of deixis, it could be said that the point of orientation, the reference point (the Origo in Bühler's terminology) is too narrowly associated with the speaker. Regarding dejctic words, the main complication to be aware of is that they can also operate relative to a reference point which is not necessarily the actual situation of utterance, not obligatorily the speaker. Deixis in its broad sense, is "a marking off point" in relation to which persons, objects and events of reality are characterized. The "point of orientation" concept is expanded to take into account the distinct situation of utterance (Ерзинкян, 1988).

The issue becomes a clcarly pragmalinguistic one when the speaker uses deictic means in a way that they convey the intended illocutionary force or politeness value.

The use of the pronoun $I$ might not always refer to the speaker. As K. Wales states, for example, utterances with should (e.g. I should ring them up), that would usually be used for giving advice, might be interpreted as: not $I$ but "you" is meant. In other words, although the pronoun $l$ is used in the above sentence, it might be obvious from the context that the hearer/addressee is targeted and the use of $I$ might be a way of "masking" role relations. In other words, what is implied in most cases is an utterance saying: "if I were you" (Wales, 1996: 69).

Let us consider another example with reference to the speaker: Can I comelgo with you? or May I come/go with you? The speaker is asking for permission rather than associating the addressee with the action; whereas the implication is that the couple/addressee is expected to take the speaker to the destination they are going to. Furthennore, this is not a permission-tequesting utterance proper; it could be classified under the so-called permission directives (Ervin-Tripp, 1976: 29) too, which include such questions as 'Can I...?' or 'May I...?'

Besides, the deictic verb come implies more paticipation and co-operation in English, whereas go is associated with distance and less participation. The semantic description of these deictic motion verbs, as well as their counterparts bring and take, needs the mention of something about the location of the interlocutors: come and bring indicate motion toward the location of the speaker at coding time; go and take indicate 
motion toward a location which is distinct from the speaker's location at coding time. Thus, come and bring taken as positive politeness strategies might be perceived as "laking the role of the other's point of view" (Brown\&Levinson, 1987: 121). And it seems that the perspective of the utterance is related in some cases to the type of the verb chosen for the act.

One of the derivative usages of deixis, in which "deictic expressions are used in ways that shift the deictic centre to other participants" is called 'deictic projection' (Lyons, 1977: 579) or 'point of view or perspective' (Fillmore, 1997:101). This phenomenon can be shown clearly in the usage of deictic predicates come and go. Compare the following sentences: I'll come to your parfy/lecture and I'll go to your party/lecture. We will probably utter the sentence I'll come to your party/lecture. when we are invited to the party/lecture of the addressee. This expression is obviously used by the speaker, and is referring to the speaker by the pronoun $I$. And the deictic centre might be expected to be at the speaker, however, it is not. The deictic centre of the sentence in this case, is at the addressee; it is preconditioned by the usage of the verb come, which refers to the action of the speaker from the addressee's point of view. In other words, this sentence is uttered from the addressee's perspective by the speaker, referring to the action of the speaker. Therefore, this expression is considered a deictic-projectional expression. In other words the deictic projectional point of view is based on the idea that a certain utterance, whose centre is supposed to be at the speaker, is uttered as if its centre were at the addressee. even though the utterance explicitly expresses an action of the speaker by the speaker himself.

To describe the same action, one can use the sentence $f$ 'll go to your party/lecture. This sentence, on the other hand, is uttered from the speaker's point of view, and due to the meaning of the verb go refers to the action of the speaker from the speaker's perspective. Therefore, such a sentence can be considered a typical deictically anchored expression.

It is said generally that politeness plays an important role in choosing one of the expressions. The sentence with come is interpreted as more polite than the one with go because of being addressee-centred: it implies more participation and cooperation in English.

Similarly, in the examples given below, the sentence with bring is interpreted as more polite than the sentence with take. Cf. I'll bring my wife to your party and I'll take my nife to your party. Thus, politeness has the so-calted "addressee-centeredness" as its basis.

If we consider the usage of these verbs in a person-deictically-anchored discourse, that is in which the speaker and the hearer/addressee figure as relevant landmarks, we can observe the shift in person-deictic centre which illustrates the derivative usage of deixis and is especially interesting as a means of conveying politeness. As Ch.Fillmore puts it, "In polite or deferential utterances, the deictic center can be assigned to the addressee". This first of all applies to the motion verbs in English - come, go, bring, take (Fillmore, 1997: 100-101).

The varying degree of politeness illustrated in examples correlates with a shift away 
from the speaker's point of reference in speaking, i.e. away from an egocentric focus toward a greater distance from the centre. This shift may be expressed formally in the choice of person reference. The person reference strategy signals the degree to which the speaker relinquishes linguistic control and becomes increasingly dependent on the will of the addressee in complying with the request, thus mitigating the force of the request.

Thus, for greater degrees of politeness, one should minimize the speaker's egocentric role in the utterance. For example, we can see this principle functioning in the linear sequencing: ny mother and $I$ went to... which is more polite than $I$ and my mother.... Likewise. it is more polite to defocalize the speaker's role in giving orders or assertions and to focalize the listener's role in the speech act. The so-called defocalisation may affect the framing of the utterance to reflect the emphasis on the hearer's role.

The strategy of defocalisation is defined in linguistics as a distancing technique used by the speaker "to minimize his/her own role or that of the hearer". Not specifying the hearer's or the speaker's involvement in the act can serve as a face-saving strategy. It is said that such forms or constructions suppress "the identity of the participants in the speech act" and enable "avoiding a direct confrontation with hearer" (Haverkate, 1992: 516). This phenomenon is dealt with as impersonalisation by Brown and Levinson (Brown\&Levinson, 1987: 190). For example, impersonal and passive constructions are considered to be more polite due to $I$ and you avoidance by the speaker in order not to be perceived as impinging on the addressee. This results in shifts away from the deictic centre, for the pronouns $I$ and $y o y$ entail direct reference to the participants, which are said to "encode the perception of intentionality" and hence may be considered as facethreatening (Brown\&Levinson, 1987). This technique of unspecified reference is widely used in indirect speech acts, which are considered more polite than direct speech acts.

The shift in focus from the deictic centre in person reference is a strategy commonly used to convey degrees of politeness in the speech act. Utterances which are framed from the addressee's instead of the speaker's point of view are considered more polite. That is. those utterances that are 'hearer-based' conveying that the hearer is in a higher position of control to decide whether or not to comply with the request are generally more polite than those that are speaker-based, or those which convey the speaker's wants and perspective. The examples in person deixis support the conclusion that the greater the distance from the deictic centre, the greater the degree of politeness and less the degree of illocutionary force stemming from the relationship to the speaker's egocentric deictic reference.

To sum up, all the issues discussed are directly connected with pragmatic competence which entails a variety of abilities concerned with the use and interpretation of language in context. It includes speaker's ability to use language for different purposes - to request, to instruct, to effect change, etc. It also includes lisiener's ability to understand the speaker's real intentions, especially when these intentions are not directly conveyed in the forms. 


\section{References}

1. Clark H. Using Language. Cambridge, Cambridge University Press, 1996.

2. Ervin-Tripp S. Is Sybil there? The Structure of Some American English Directives // Language in Society, 5, 1976.

3. Fillmore Ch. Lectures on Deixis. Stanford, 2001.

4. Goffman E. Interaction Ritual: Essays on Face-to-Face Behavior. New York, 1967.

5. Haverkate H. Deictic Categories as Mitigating Devices // Pragmatics, 1992, 2 (4) 1975 .

6. Koike D. Requests and Politeness // Journal of Pragmatics, 13, 1989.

7. Lakoff $\mathrm{R}$. Language in Context // Language, 48, 1972.

8. Lakoff R. The logic of politeness, or minding your p's and q's. // Papers from the Ninth Regional Meeting of the Chicago Linguistics Society. Chicago, 1973.

9. Leech G. Principles of Pragmatics. London\&New York: Longman, 1983.

10. Brown P., Levinson S. Universals in Language Usage: Politeness Phenomenon. // Questions and Politeness: Strategies in Social Interaction. / Goody E. (ed.). Cambridge, Cambridge University Press, 1978; 1987.

11. Lyons J. Semantics. Vol. 2. Cambridge, Cambridge University Press, 1977.

12. Wales K. Personal Pronouns in Present-Day English. Cambridge, Cambridge University Press, 1996.

13. Ерзинкян Е.Л. Дейкгическая семантика слова. Ереван, Изд-во ЕГУ, 1988.

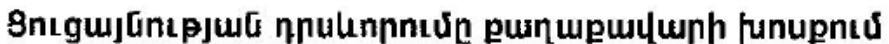

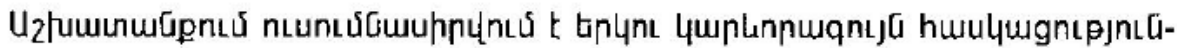

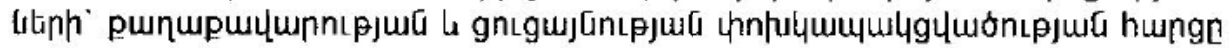

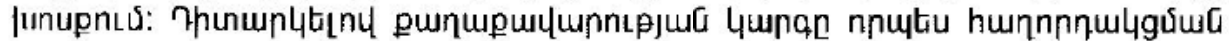

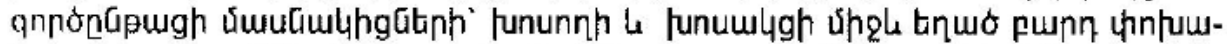

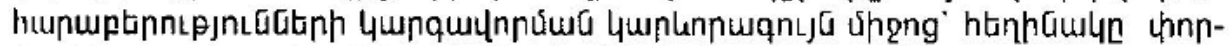

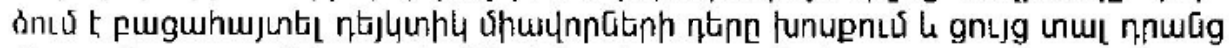

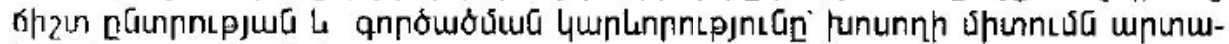

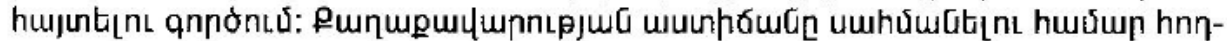

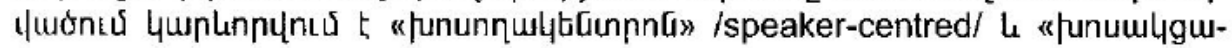

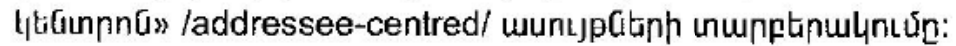

